\title{
Effect of pill burden on dosing preferences, willingness to pay, and likely adherence among patients with type 2 diabetes
}

This article was published in the following Dove Press journal:

Patient Preference and Adherence

17 September 2013

Number of times this article has been viewed

\author{
A Brett Hauber' \\ Steven $\mathrm{Han}^{2,3}$ \\ Jui-Chen Yang' \\ Ira Gantz ${ }^{2}$ \\ Kaan Tunceli² \\ Juan Marcos Gonzalez' \\ Kimberly Brodovicz ${ }^{2}$ \\ Charles M Alexander ${ }^{2}$ \\ Michael Davies ${ }^{2}$ \\ Kristy Iglay ${ }^{2}$ \\ Qiaoyi Zhang ${ }^{2}$ \\ Larry Radican ${ }^{2}$
}

'Health Preference Assessment, Research Triangle Institute (RTI) Health Solutions, Research Triangle Park, NC, USA; ${ }^{2}$ Merck Sharp and Dohme Corporation, Whitehouse Station, NJ, USA; ${ }^{3}$ Temple University, Philadelphia, PA, USA
Correspondence: A Brett Hauber RTI Health Solutions, 200 Park Offices Drive, PO Box 12194, Research Triangle Park, NC, 27709, USA

$\mathrm{Tel}+$ I 9195975149

Fax + I 9195417222

Email abhauber@rti.org
Purpose: To quantify willingness-to-pay (WTP) for reducing pill burden and dosing frequency among patients with type 2 diabetes mellitus (T2DM), and to examine the effect of dosing frequency and pill burden on likely medication adherence.

Patients and methods: Participants were US adults with T2DM on oral antihyperglycemic therapy. Each patient completed an online discrete-choice experiment (DCE) with eight choice questions, each including a pair of hypothetical medication profiles. Each profile was defined by reduction in average glucose (AG), daily dosing, chance of mild-to-moderate stomach problems, frequency of hypoglycemia, weight change, incremental risk of congestive heart failure $(\mathrm{CHF})$, and cost. Patients were asked to rate their likely adherence to the profiles presented in each question. Choice questions were based on a predetermined experimental design. Choice data were analyzed using random-parameters logit. Likely treatment adherence was analyzed using a Heckman two-stage model.

Results: Of the 1,114 patients who completed the survey, 90 had lower dosing burden $(<5$ pills/day taken once/day or as needed) for all medications, and 1,024 had higher dosing burden ( $\geq 5$ pills/day or more than once/day). Reduction in AG was valued most highly by patients. Hypoglycemia, chance of mild-to-moderate stomach problems, weight change, incremental risk of CHF, and daily dosing were less valued. Patients with higher current dosing burden had lower WTP for more convenient dosing schedules than patients with lower current dosing burden. Changes in dosing and cost impacted likely adherence. The magnitude of the impact of dosing on likely adherence was higher for patients with lower current dosing burden than for patients with higher current dosing burden.

Conclusion: Patients with T2DM were willing to pay for improvements in efficacy, side effects, and dosing. Patients' WTP for more convenient dosing depended on current dosing burden, as did the effect of these attributes on likely adherence.

Keywords: discrete-choice experiment, conjoint analysis, willingness to pay, adherence, type 2 diabetes mellitus, oral antihyperglycemic therapy

\section{Introduction}

According to the 2011 National Diabetes Fact Sheet, 25.8 million people in the United States (US) (or $8.5 \%$ of the US population) have either diagnosed or undiagnosed diabetes. In 2010 alone, approximately 1.9 million Americans aged 20 years or older received a new diagnosis of diabetes. ${ }^{1}$ A 2007 estimate of diabetes costs totaled US\$174 billion, which included direct medical costs of US\$116 billion and indirect costs of US\$58 billion due to disability, work loss, and premature mortality. ${ }^{1}$

A recent National Diabetes Fact Sheet ${ }^{1}$ reported that among adults with physiciandiagnosed diabetes, more than $70 \%$ took oral medication with or without insulin. 
Major classes of oral diabetes medication include sulfonylureas (SU), meglitinides, biguanides, thiazolidinediones, alpha-glucosidase inhibitors, dipeptidyl peptidase-4 (DPP-4) inhibitors, and sodium-glucose co-transporter 2 (SGLT2) inhibitors. ${ }^{2}$ These medications can be taken as monotherapies or as combination therapies.

Type 2 diabetes mellitus (T2DM) is a progressive disease, and with time patients often require treatment with combination therapy. ${ }^{3,4}$ However, combination therapies often increase dosing frequency and pill burden for patients with T2DM. To reduce the dosing burden associated with combination therapies and increase patient convenience, fixed-dose combination formulations have been developed. These have shown similar treatment efficacy and side effects comparable to the combination of individual therapies in several studies. ${ }^{5-7}$ Other published studies have suggested that less frequent dosing may result in greater patient adherence, improved treatment outcomes, and reduced health care costs. ${ }^{8-11}$

The primary objective of this study was to use a discretechoice experiment (DCE) to quantify patients' preferences for and the value of reducing dosing frequency and pill burden relative to improvements in other attributes of oral antihyperglycemic agents. The secondary objective of this study was to quantify the effect of dosing frequency and pill burden on likely medication adherence.

\section{Material and methods}

\section{Study and survey design}

DCEs, also known as choice-format conjoint analysis studies, have been increasingly used to determine the tradeoffs patients are willing to make among features of medical interventions. ${ }^{12-14}$ This method is based on the premise that medical interventions are composed of a set of attributes or outcomes, that the attractiveness of a particular intervention to an individual is a function of these attributes, and that choices among alternatives reveal patients' relative preferences for these attributes. ${ }^{15}$ When out-of-pocket cost is included as a medication attribute in a DCE, the results can be used to calculate the value of or willingness-to-pay (WTP) for improvements in medication attributes. ${ }^{16-18}$ DCEs have also been used to elicit patients' ratings of the effect of medication attributes on likely medication adherence. ${ }^{19-22}$

The DCE survey was designed to present a series of eight choice questions; each question presented a pair of hypothetical oral medication profiles. Each profile was defined by five clinical outcomes, daily dosing schedule, and out-of-pocket cost. Clinical outcomes included reduction in average glucose (AG), chance of mild-to-moderate stomach problems, frequency of hypoglycemia, weight change within the first 6 months after starting treatment, and incremental treatment-related risk of congestive heart failure (CHF). Relevant clinical attributes and daily dosing options were identified based on a review of clinical literature and product labels for oral antihyperglycemic medications and consultation with clinic experts. The clinical attributes were chosen to include those attributes in which differences appear to exist between different dual- and fixed-dose combination therapies. The sources reviewed are presented in Table S1.

The ranges of the attribute levels were chosen to encompass the range of outcome levels described in the clinicaltrials literature, as well as the range over which patients were willing to accept tradeoffs. The levels of the dosing attribute included recommended dosing for fixed-dose combinations of immediate release (IR) sitagliptin-metformin and extended release (XR) sitagliptin-metformin, as well as dual therapies including pioglitazone plus SU, dipeptidyl peptidase-4 (DPP-4) inhibitor plus metformin, pioglitazone plus metformin, and metformin plus SU. However, the presentation of the dosing attribute in the survey was shown independent of these medications. Out-of-pocket cost was included as an attribute in the choice questions to enable us to estimate WTP for changes in the levels of the clinical and dosing attributes. The range of levels for the cost attribute was chosen to encompass the range over which patients were willing to accept tradeoffs between cost and different levels of the clinical attributes. The saliency of these attributes to patients was confirmed during 14 face-to-face pretest interviews with a convenience sample of patients with T2DM. The levels and analytical variable names used for each attribute are summarized in Table 1.

The seven attributes and their levels were organized into pairs of hypothetical, but realistic, medication profiles. Each profile included all seven attributes; however, the levels of the attributes varied across profiles. Patients were asked to consider the following hypothetical scenario in each of a series of choice questions: "Imagine that you go to see your doctor today and he or she tells you that you need to start a new oral diabetes medicine because your average blood sugar level is $206 \mathrm{mg} / \mathrm{dL}$ (uncontrolled)". For each pair of hypothetical medications, patients were then asked to indicate which medication they would choose if the two profiles in each question represented the only medication options available. Figure 1 presents an example choice question. A fractional 
Table I Diabetes attributes and levels

\begin{tabular}{|c|c|c|}
\hline Attribute & Levels & $\begin{array}{l}\text { Variable } \\
\text { name }\end{array}$ \\
\hline (baseline: 206 mg/dL) & $\begin{array}{l}66 \mathrm{mg} / \mathrm{dL}(2.3 \%) \\
58 \mathrm{mg} / \mathrm{dL}(2.0 \%) \\
55 \mathrm{mg} / \mathrm{dL}(1.9 \%) \\
32 \mathrm{mg} / \mathrm{dL}(1.1 \%) \\
20 \mathrm{mg} / \mathrm{dL}(0.7 \%)\end{array}$ & See notes \\
\hline \multirow[t]{4}{*}{ Daily dosing schedule } & $\begin{array}{l}\text { One pill in the morning, } \\
\text { one in the evening }\end{array}$ & DOSEI \\
\hline & Two pills in the evening & DOSE2 \\
\hline & $\begin{array}{l}\text { Two pills in the morning, } \\
\text { one in the evening }\end{array}$ & DOSE3 \\
\hline & $\begin{array}{l}\text { Three pills in the morning, } \\
\text { three in the evening }\end{array}$ & DOSE4 \\
\hline Chance of mild-to- & 10 out of 100 people & STOMI \\
\hline moderate stomach & 23 out of 100 people & STOM2 \\
\hline \multirow[t]{2}{*}{ problems } & 25 out of 100 people & STOM3 \\
\hline & 30 out of 100 people & STOM4 \\
\hline \multirow[t]{4}{*}{ Hypoglycemia (event) } & No hypoglycemic episodes & HYPOI \\
\hline & $\begin{array}{l}\text { One to two hypoglycemic } \\
\text { episodes per year }\end{array}$ & HYPO2 \\
\hline & $\begin{array}{l}\text { One to two hypoglycemic } \\
\text { episodes per month }\end{array}$ & HYPO3 \\
\hline & $\begin{array}{l}\text { More than two hypoglycemic } \\
\text { episodes per month }\end{array}$ & HYPO4 \\
\hline Weight change within & $6 \mathrm{lb}$ weight gain & WGTI \\
\hline the first 6 months of & $3 \mathrm{lb}$ weight gain & WGT2 \\
\hline \multirow[t]{3}{*}{ starting treatment } & No weight change & WGT3 \\
\hline & $3 \mathrm{lb}$ weight loss & WGT4 \\
\hline & $6 \mathrm{lb}$ weight loss & WGT5 \\
\hline Additional chance & No additional chance of $\mathrm{CHF}$ & CHFI \\
\hline \multirow[t]{2}{*}{ of $\mathrm{CHF}$} & Additional I out of I00 people & CHF2 \\
\hline & Additional 3 out of 100 people & CHF3 \\
\hline Out-of-pocket cost & $\$ 0$ per month & COSTI \\
\hline \multirow[t]{3}{*}{ of the medicine } & $\$ 25$ per month & COST2 \\
\hline & $\$ 100$ per month & COST3 \\
\hline & $\$ 200$ per month & COST4 \\
\hline
\end{tabular}

Note: The additional chance of CHF is the absolute increase in risk above a baseline risk of $8 \%$. Three variables, HIAGRDX, LOAGRDX, and GOOD_CONTROL, were created for the glucose control attribute. HIAGRDX, a continuous variable, was set at the level shown (ie, $55 \mathrm{mg} / \mathrm{dL}, 58 \mathrm{mg} / \mathrm{dL}$, or $66 \mathrm{mg} / \mathrm{dL}$ ) in each hypothetical diabetes medicine when a controlled AG was offered (ie, a reduction in $A G \geq 55 \mathrm{mg} / \mathrm{dL}$ ); otherwise, HIAGRDX was set at 0 . Similarly, LOAGRDX, a continuous variable, was set at the level shown (ie, $20 \mathrm{mg} / \mathrm{dL}$ or $32 \mathrm{mg} / \mathrm{dL}$ ) when an uncontrolled AG was offered (ie, a reduction in AG $<55 \mathrm{mg} / \mathrm{dL}$ ); otherwise, LOAGRDX was set at 0 . GOOD CONTROL, a dummy variable, was equal to one when a controlled $A G$ was offered (ie, a reduction in $A G \geq 55 \mathrm{mg} / \mathrm{dL}$ ); otherwise, GOOD_CONTROL was set at 0 . Abbreviations: AG, average glucose; $\mathrm{CHF}$, congestive heart failure.

factorial experimental design with 80 choice questions was constructed with a commonly used D-optimal algorithm..$^{23-28}$ The experimental design was developed such that the combinations of attribute levels that define each profile and the pairing of profiles are independent of the relative placement of a profile in a pair (ie, left side or right side). In addition, the profiles have generic labels so the labels themselves should not convey any meaning over which patients have preferences. As a result, a person who chooses Medicine A (or Medicine B) in every choice question is more than likely not paying attention to the choice questions and the responses to the questions reflect a strategy for completing the survey rather than an expression of preference. Therefore, patients who always chose Medicine A or Medicine B in the series of choice questions were excluded from the analysis. The 80 choice questions were divided into ten versions of eight questions each. Each patient was randomly assigned to one of the ten versions.

After each choice question, patients were asked how likely they would be to miss or skip doses of each of the hypothetical T2DM medications presented in the choice questions (see Figure 1). The relative likelihood of missing or skipping doses for each pair of treatment profiles was rated on a Likert scale ranging from "much more likely to miss or skip doses with Medicine A" to "much more likely to miss or skip doses with Medicine B". "Equally likely to miss or skip doses with Medicine A and Medicine B" was the midpoint. During the pretest interviews, it became apparent that respondents who indicated that they never missed or skipped doses were unable or unwilling to answer the adherence follow-up questions. Therefore, the adherence follow-up questions were asked only of those respondents who indicated that they had missed or skipped doses at least occasionally.

The survey also collected data on demographic characteristics, health history, and treatment experience. The study and survey design were approved by Research Triangle Institute's Office of Research Protection and Ethics. A copy of the survey is available from the corresponding author upon request.

\section{Data collection}

Patients were recruited from the Knowledge Networks online patient panel. Knowledge Networks is a survey research firm that conducts online research. It develops and manages the online probability-based panel called KnowledgePanel ${ }^{\circledR}$ (Knowledge Networks, Palto Alto, CA, USA) that is representative of the US population. KnowledgePanel ${ }^{\circledR}$ contains over 4,500 variables collected on each panelist, including various medical conditions such as T2DM. More details about the panel are available at http://www.knowledgenetworks.com/knpanel/index.html. To qualify for inclusion in this study, patients had to (1) be aged 18 years or older; (2) have a self-reported physician diagnosis of T2DM; (3) be currently taking oral antihyperglycemic agent(s); and (4) be not currently taking injectable T2DM treatments (eg, insulin 


\begin{tabular}{|c|c|c|c|c|c|c|}
\hline Medicine feature & \multicolumn{3}{|c|}{ Medicine A } & \multicolumn{3}{|c|}{ Medicine B } \\
\hline \multirow{4}{*}{$\begin{array}{l}\text { Decrease in average } \\
\text { blood sugar level }\end{array}$} & \multirow{2}{*}{\multicolumn{3}{|c|}{ 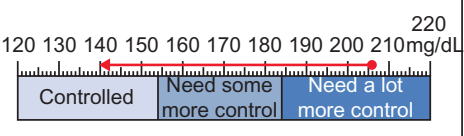 }} & \multirow{2}{*}{\multicolumn{3}{|c|}{ 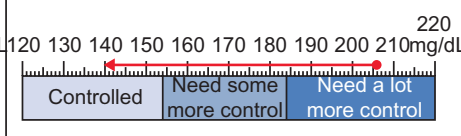 }} \\
\hline & & & & & & \\
\hline & \multirow{2}{*}{\multicolumn{3}{|c|}{$\begin{array}{c}\mathrm{P} \\
\text { Morning }\end{array}$}} & \multirow{2}{*}{\multicolumn{3}{|c|}{$\begin{array}{c}8 \\
\text { Morning }\end{array}$}} \\
\hline & & & & & & \\
\hline $\begin{array}{l}\text { Chance of stomach } \\
\text { problems }\end{array}$ & \multicolumn{3}{|c|}{ 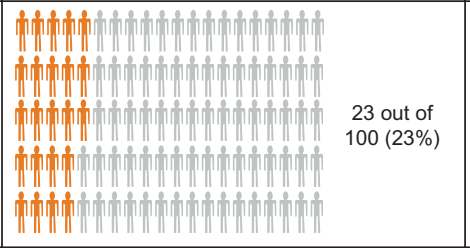 } & \multicolumn{3}{|c|}{ 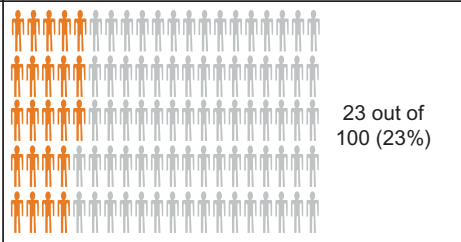 } \\
\hline $\begin{array}{l}\text { Frequency of low } \\
\text { blood-sugar episodes }\end{array}$ & \multicolumn{3}{|c|}{$1-2$ per month ( $12-24$ per year) } & \multicolumn{3}{|c|}{ 1-2 per year } \\
\hline Weight change & \multicolumn{3}{|c|}{ No weight change } & \multicolumn{3}{|c|}{ No weight change } \\
\hline $\begin{array}{l}\text { Increased chance } \\
\text { of CHF }\end{array}$ & \multicolumn{3}{|c|}{ 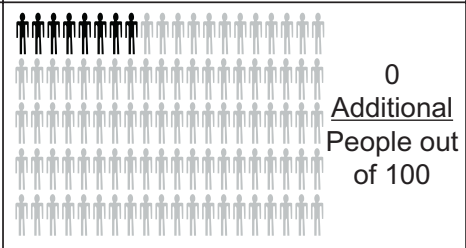 } & \multicolumn{3}{|c|}{ 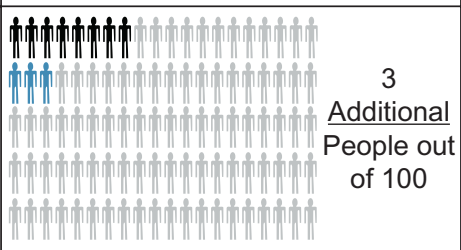 } \\
\hline Personal medicine cost & \multicolumn{3}{|c|}{$\$ 200$ per month } & \multicolumn{3}{|c|}{$\$ 100$ per month } \\
\hline $\begin{array}{c}\text { Which medicine would } \\
\text { you choose if these } \\
\text { were the only two } \\
\text { medicines available? }\end{array}$ & \multicolumn{3}{|c|}{ Medicine A } & \multicolumn{3}{|c|}{ Medicine B } \\
\hline $\begin{array}{c}\text { How likely would you be } \\
\text { to miss or skip doses } \\
\text { of each medicine? }\end{array}$ & $\begin{array}{l}\text { Much more } \\
\text { likely to } \\
\text { miss or skip } \\
\text { doses with } \\
\text { Medicine A }\end{array}$ & $\begin{array}{l}\text { A little more } \\
\text { likely to } \\
\text { miss or skip } \\
\text { doses with } \\
\text { Medicine A }\end{array}$ & $\begin{array}{l}\text { Equally } \\
\text { to miss } \\
\text { doses } \\
\text { Medicin } \\
\text { Medic }\end{array}$ & $\begin{array}{l}\text { likely } \\
\text { or skip } \\
\text { with } \\
\text { e A and } \\
\text { ine B }\end{array}$ & $\begin{array}{l}\text { A little more } \\
\text { likely to } \\
\text { miss or skip } \\
\text { doses with } \\
\text { Medicine B }\end{array}$ & $\begin{array}{l}\text { Much more } \\
\text { likely to } \\
\text { miss or skip } \\
\text { doses with } \\
\text { Medicine B }\end{array}$ \\
\hline
\end{tabular}

Figure I Example choice question.

Abbreviation: $\mathrm{CHF}$, congestive heart failure.

and glucagon-like-1 receptor agonist). Email invitations were sent to potential panelists based on their self-reported physician-diagnosis of T2DM. Survey participants received Knowledge Networks points (nonmonetary compensation) for their participation in the study. The survey was available to invited participants between March 18, 2011 and April 6, 2011.

\section{Data analysis}

The medication choice data were analyzed using a randomparameters logit model with NLOGIT 4.0 (Econometric Software, Inc, Plainview, NY, USA). All of the attributes listed in Table 1 (except reduction in AG) were included in the model as effects-coded categorical variables. Reduction in AG was specified as a continuous variable. With effects coding, zero indicates the mean effect across all attribute levels, rather than the omitted level as in dummy coding. This procedure produces a parameter estimate for all attribute levels, where the parameter on the omitted level of each attribute is the negative sum of the parameters on the other levels of that attribute. The resulting log-odds estimates can be interpreted as relative preference weights.

During the pretest interviews, we observed that patients' answers to both the choice questions and the adherence ratings appeared to be systematically different between those patients who took more medications, more often, and those who took fewer medications, less often. We accounted for this difference by estimating separate parameters for each of the levels of dosing for those who took more medications (heavy users) and those who took fewer medications (light users). Heavy users and light users were defined by determining the combinations of pill burden and dosing frequency 
for which the greatest differences in dosing preferences were observed.

The following model was estimated:

$$
\begin{aligned}
& U=\beta_{\text {HIAGRDX }} \times \text { HIAGRDX }+\beta_{\text {LOAGRDX }} \times \text { LOAGRDX } \\
& +\beta_{\text {GOOD_CONTROL }} \times \text { GOOD_CONTROL }+ \text { LITE } \\
& \times\left(\beta_{\text {DOSE }} \times \text { DOSE } 1+\beta_{\text {DOSE } 2} \times \text { DOSE } 2+\beta_{\text {DOSE } 3}\right. \\
& \left.\times \text { DOSE } 3+\beta_{\text {DOSE } 4} \times \text { DOSE } 4\right)+ \text { HVY } \times\left(\beta_{\text {DOSE } 1}\right. \\
& \times \text { DOSE } 1+\beta_{\text {DOSE } 2} \times \text { DOSE } 2+\beta_{\text {DOSE } 3} \times \text { DOSE } 3 \\
& \left.+\beta_{\mathrm{DOSE} 4} \times \text { DOSE } 4\right)+\beta_{\mathrm{STOM} 1} \times \mathrm{STOM} 1+\beta_{\mathrm{STOM} 2} \\
& \times \mathrm{STOM} 2+\beta_{\text {STOM } 3} \times \mathrm{STOM} 3+\beta_{\mathrm{STOM} 4} \times \mathrm{STOM} 4 \\
& +\beta_{\mathrm{HYPO} 1} \times \mathrm{HYPO} 1+\beta_{\mathrm{HYPO} 2} \times \mathrm{HYPO} 2+\beta_{\mathrm{HYPO} 3} \\
& \times \mathrm{HYPO} 3+\beta_{\mathrm{HYPO} 4} \times \mathrm{HYPO} 4+\beta_{\mathrm{WGT} 1} \times \mathrm{WGT} 1 \\
& +\beta_{\mathrm{WGT} 2} \times \mathrm{WGT} 2+\beta_{\mathrm{WGT} 3} \times \mathrm{WGT} 3+\beta_{\mathrm{WGT} 4} \\
& \times \mathrm{WGT} 4+\beta_{\mathrm{WGT} 5} \times \mathrm{WGT} 5+\beta_{\mathrm{CHF} 1} \times \mathrm{CHF} 1+\beta_{\mathrm{CHF} 2} \\
& \times \mathrm{CHF} 2+\beta_{\mathrm{CHF} 3} \times \mathrm{CHF} 3+\beta_{\mathrm{COST} 1} \times \mathrm{COST} 1+\beta_{\mathrm{COST} 2} \\
& \times \operatorname{COST} 2+\beta_{\mathrm{COST} 3} \times \operatorname{COST} 3+\beta_{\mathrm{cosT} 4} \times \operatorname{COST} 4+\varepsilon \text {, }
\end{aligned}
$$

where $U$ was the implicit ordinal utility for each medicine profile, LITE was a dummy variable (equal to 1 if patients were classified as light users), HVY was equal to 1 minus LITE, and $\varepsilon$ was the error term. Other variables are as defined in Table 1.

The preference weights were used to calculate WTP for improvements in daily dosing schedules. WTP is the mean maximum monetary equivalent that an individual is willing to pay for a given improvement in dosing. WTP is the increase in out-of-pocket cost that yields a decrease in estimated utility that exactly offsets the increase in utility yielded by an improvement in dosing. For example, WTP for an improvement in dosing from three pills twice a day (DOSE4) to 2 pills in the evening (DOSE2) is calculated as the level of cost (X) that satisfies $-\beta_{\text {COST }(X)}=\beta_{\text {DOSE } 2}-\beta_{\text {DOSE4 }}$. Because the levels of cost are categorical, X may lie between two cost levels. Therefore, we interpolated linearly between the preference estimates for the surrounding cost levels to find the value of $\mathrm{X}$.

To analyze patients' ratings of likely treatment adherence, a Heckman two-stage model was employed using NLOGIT 4.0. ${ }^{29-31}$ In the first stage, a probit model was estimated with a dependent variable indicating whether a patient chose a response other than "equally likely to miss or skip doses with Medicine A and Medicine B" and patientspecific characteristics as explanatory variables. This stage of the model was estimated to quantify the effect of patients' characteristics on the probability that they would miss or skip doses based on the attributes of the medications presented in the study. In the second stage of the model, patients' ratings of the likelihood of missing or skipping doses were modeled as a function of medication attributes. An ordered-probit model was estimated in which the levels of the treatment attributes were used to predict the likelihood of choosing an adherence rating; this model incorporated the results of the first stage by controlling for patients who indicated that treatment attributes would likely not affect their likelihood of missing or skipping doses. The second stage of the model, therefore, describes the effect of medication attributes on likely adherence, controlling for the fact that for some patients and in some cases medication attributes may have no effect on likely adherence.

\section{Results Characteristics of the study sample}

A total of 2,039 email invitations were sent to members of the KnowledgePanel ${ }^{\circledR}$. One thousand four hundred and ninetyeight $(1,498)$ individuals responded to the invitation. The response rate was $73.5 \%$. One thousand, one hundred and fifty-three $(1,153)$ patients met the inclusion criteria for the study, of which 1,135 consented and completed the survey. Of the 1,135 patients who completed the survey, 20 were excluded from the analysis because they had no variation in their responses - they chose either Medicine A or Medicine $\mathrm{B}$ for every choice question. This response pattern indicated that the patient was inattentive to the choice questions. One additional patient who did not report his or her current dosing burden was also excluded from the analysis.

The characteristics of the remaining 1,114 patients are summarized in Table 2. The mean age was 62 years. The majority of the patients were male (approximately 54\%), were white and non-Hispanic (approximately 79\%), and had at least some college education (72\%). Approximately $37 \%$ of the patients were working. Median annual household income was between US\$50,000 and US\$74,999.

\section{Patients' preferences for treatment attributes}

Patients were classified as light users if they took fewer than five pills per day for all their health conditions or took medications only once a day or as needed. Patients were classified as heavy users if they took five or more pills per day for all their health conditions or took medications more than once a day. Descriptive statistics of demographic characteristics and disease and treatment histories were calculated for all patients and by dosing classification. Among the 1,114 patients, 90 were classified as light users, and 1,024 were classified as heavy users.

Figure 2 presents the log-odds preference weights relative to the mean attribute effect normalized at zero. 
Table 2 Characteristics of the study sample

\begin{tabular}{|c|c|c|c|}
\hline Characteristic & $\begin{array}{l}\text { All patients } \\
\mathrm{n}=\mathrm{I}, \mathrm{I} \mid \mathbf{4}\end{array}$ & $\begin{array}{l}\text { Patients with low } \\
\text { current-dosing burden } \\
\mathbf{n}=90\end{array}$ & $\begin{array}{l}\text { Patients with high } \\
\text { current-dosing burden } \\
n=1,024\end{array}$ \\
\hline Mean age (SD) & $62.1(11.1)$ & $57.0(1 \mathrm{I} .8)$ & $62.5(10.9)$ \\
\hline Male & $599(53.8 \%)$ & 49 (54.4\%) & $550(53.7 \%)$ \\
\hline \multicolumn{4}{|l|}{ Race/ethnicity } \\
\hline White, non-Hispanic & $875(78.5 \%)$ & $59(65.6 \%)$ & $816(79.7 \%)$ \\
\hline Black, non-Hispanic & $126(11.3 \%)$ & 21 (23.3\%) & $105(10.3 \%)$ \\
\hline Hispanic & $55(4.9 \%)$ & $6(6.7 \%)$ & $49(4.8 \%)$ \\
\hline Other & $58(5.2 \%)$ & $4(4.4 \%)$ & 54 (5.3\%) \\
\hline \multicolumn{4}{|l|}{ Education level } \\
\hline High school diploma or less & $311(27.9 \%)$ & $29(32.2 \%)$ & $282(27.5 \%)$ \\
\hline More than high school diploma & $803(72.1 \%)$ & $61(67.8 \%)$ & $742(72.5 \%)$ \\
\hline \multicolumn{4}{|l|}{ Marital status } \\
\hline Married or living with partner & $759(68.1 \%)$ & $62(68.9 \%)$ & $697(68.1 \%)$ \\
\hline Other & 355 (31.9\%) & $28(31.1 \%)$ & $327(31.9 \%)$ \\
\hline \multicolumn{4}{|l|}{ Employment status } \\
\hline Employed & $410(36.8 \%)$ & $43(47.8 \%)$ & $367(35.8 \%)$ \\
\hline Not working & $704(63.2 \%)$ & $47(52.2 \%)$ & $657(64.2 \%)$ \\
\hline \multicolumn{4}{|l|}{ Time since diabetes diagnosis } \\
\hline Less than I year ago & $29(2.6 \%)$ & $6(6.7 \%)$ & $23(2.2 \%)$ \\
\hline $\mathrm{I}-5$ years ago & 407 (36.6\%) & $4 \mathrm{I}(45.6 \%)$ & $366(35.8 \%)$ \\
\hline More than 5 years ago & $674(60.6 \%)$ & $43(47.8 \%)$ & $631(61.7 \%)$ \\
\hline Don't know or not sure & $3(0.3 \%)$ & 0 & $3(0.3 \%)$ \\
\hline Missing & 1 & 0 & I \\
\hline \multicolumn{4}{|c|}{ Number of prescription medications taken to treat all health condition(s) } \\
\hline Mean (SD) & $5.8(3.6)$ & $2.5(1.1)$ & $6.1(3.6)$ \\
\hline Missing & 9 & 1 & 8 \\
\hline \multicolumn{4}{|l|}{ Total number of pills taken each day } \\
\hline Mean (SD) & $8.8(6.1)$ & $2.8(1.0)$ & $9.3(6.0)$ \\
\hline Missing & 8 & 1 & 7 \\
\hline \multicolumn{4}{|c|}{ Number of times each day prescription medications to treat all health condition(s) are taken } \\
\hline Once a day & $168(15.1 \%)$ & $85(95.5 \%)$ & $83(8.1 \%)$ \\
\hline Twice a day & 706 (63.5\%) & 0 & 706 (69.0\%) \\
\hline Three times a day & $162(14.6 \%)$ & 0 & $162(15.8 \%)$ \\
\hline As needed & $25(2.2 \%)$ & $4(4.5 \%)$ & $21(2.1 \%)$ \\
\hline Other & $5 I(4.6 \%)$ & 0 & 51 (5.0\%) \\
\hline Missing & 2 & I & 1 \\
\hline
\end{tabular}

Note: Percentages displayed exclude missing values.

Abbreviation: SD, standard deviation.

The vertical bars around each preference weight indicate the 95\% confidence intervals (CIs) for the estimate. Within each attribute, higher preference weights indicate more preferred outcomes and the difference (indicated by the vertical distance in Figure 2) between consecutive preference weights indicates the relative importance of moving from one level of the attribute to an adjacent level of the same attribute. For example, the level "none" for hypoglycemia has a higher preference weight than the level " $1-2$ hypoglycemic episodes per year", which in turn has a higher preference weight than "1-2 hypoglycemic episodes per month", indicating that less frequent hypoglycemia is preferred to more frequent hypoglycemia. With one exception, the estimated preference weights were consistent with the natural ordering of the attribute levels - that is, better clinical outcomes were preferred to worse clinical outcomes. The preference weight for 3-pound weight loss was greater than the preference weight for 6-pound weight loss; however, the difference between the estimated preference weights on these levels was not statistically significant $(P>0.05)$.

The difference between the preference weights for one to two hypoglycemic episodes per year and no hypoglycemic episodes is smaller than the difference between the preference weights for one to two hypoglycemic episodes per month and one to two hypoglycemic episodes per year; this difference indicates that the elimination of one to two hypoglycemic episodes per month is less important to patients than a reduction in hypoglycemic episodes from one to two hypoglycemic 


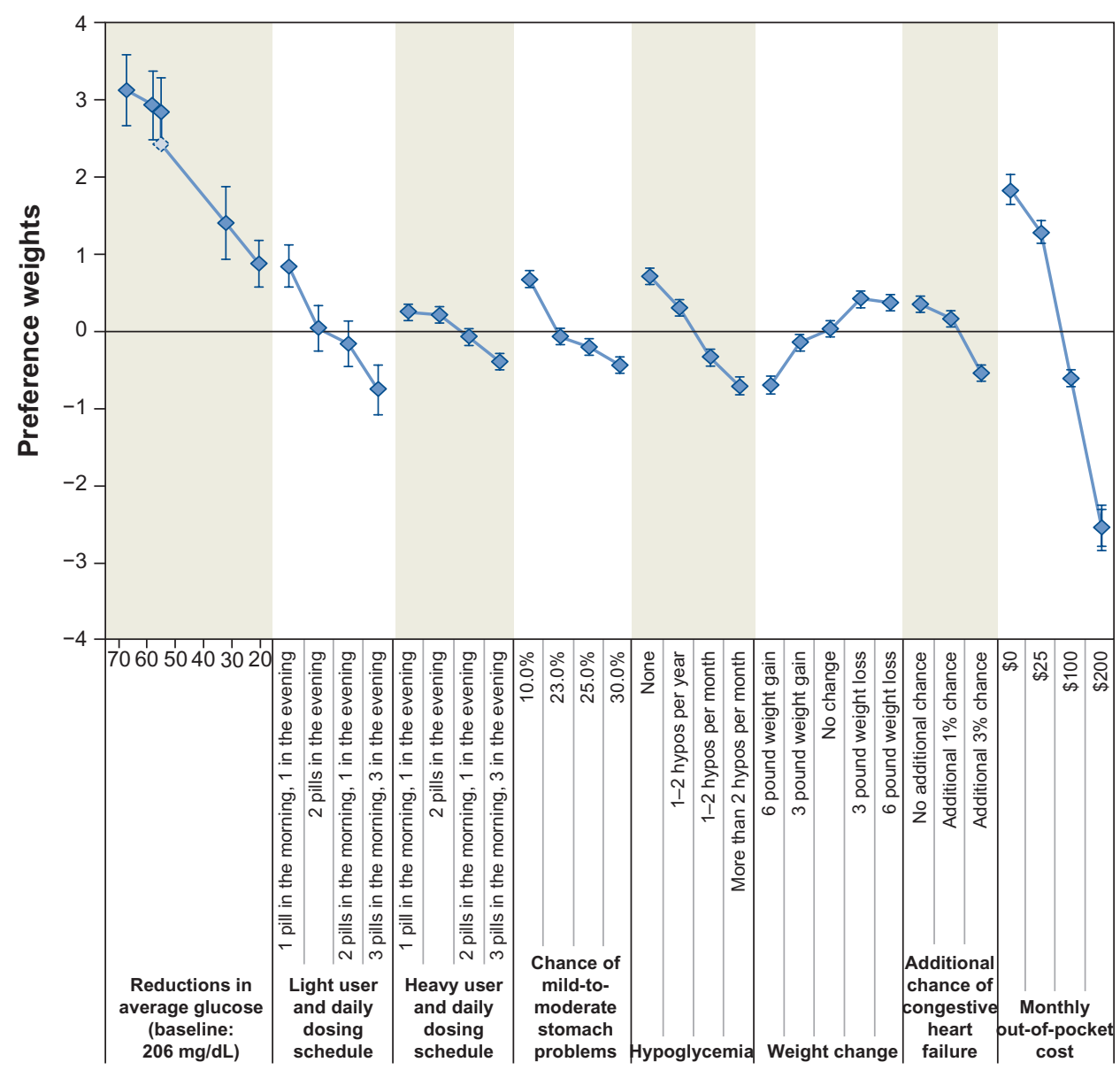

Figure 2 Preference weights $(n=1,1 \mid 4){ }^{a}$

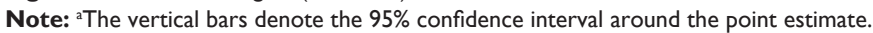

episodes per month to one to two hypoglycemic episodes per year. The difference between the preference weights of two levels of one attribute can be compared to the difference between the preference weights of two levels of a different attribute. For example, the difference between the preference weights for a $3 \%$ incremental risk of $\mathrm{CHF}$ and a $1 \%$ incremental risk of $\mathrm{CHF}$ is approximately 0.69 . The difference between the preference weights for one to two hypoglycemic episodes per year and no hypoglycemic episodes is approximately 0.63 . Therefore, reducing the incremental risk of CHF from $3 \%$ to $1 \%$ is slightly more important to patients than eliminating one to two hypoglycemic episodes per year.

As shown in Figure 2, less burdensome dosing schedules were preferred by all patients. However, patients with higher dosing burden for all medications (noted as "heavy user" in Figure 2) preferred more convenient dosing schedules less than patients with a lower dosing burden (noted as "light user" in Figure 2). For both groups, two pills daily (either two pills once a day or one pill twice a day) was preferred to three pills daily (two pills in the morning and one pill in the evening); three pills daily was preferred to six pills daily (three pills in the morning and three pills in the evening). Light users strongly preferred one pill twice a day to two pills once a day, while preferences among heavy users for the same change in pill burden was much lower. The difference in preference weights between two pills once per day and one pill twice per day is approximately 0.06 for heavy users, and approximately 4.6 for light users, indicating that such a change in dosing is approximately 7.5 times as important to light users as it is to heavy users.

Comparing the difference in preference weights between the best and worst levels of an attribute provides a measure of the overall relative importance of that attribute over the ranges of attribute levels in the survey. Using this metric, reduction in AG was the most important clinical outcome, while hypoglycemia, chance of mild-to-moderate stomach problems, weight change within the first 6 months of starting treatment, and incremental increase in the risk of CHF were of lesser importance. Reductions in daily-dosing schedule were relatively more important than increases in the chance 
of mild-to-moderate stomach problems, weight change within the first 6 months of starting treatment, and the incremental increase in the risk of CHF, but were relatively less important than hypoglycemia among light users. Among heavy users, daily-dosing schedule was less important than any of the clinical attributes.

WTP estimates for improvements in daily dosing schedule are reported in Table 3. As expected, all patients were willing to pay more for greater reductions in number of pills and WTP was generally higher for light users than for heavy users. Among both heavy users and light users, the highest WTP (95\% CI) for reductions in dosing burden was (all figures in US dollars) \$28.99 (\$19.38-\$38.51) per month and was associated with changing from three pills twice a day to one pill twice a day. Among heavy users, the lowest WTP was $\$ 1.50$ (\$0.11-\$8.44) per month for a change from two pills once a day to one pill twice a day. Among light users, the highest WTP was \$66.59 (\$45.45-\$87.09) per month for a change from three pills twice a day to one pill twice a day. Among light users, the lowest WTP was \$8.97 (\$0.44-\$30.58) for a change from two pills in the morning plus one pill in the evening to two pills in the evening. Furthermore, light users valued a change from two pills in the evening to one pill twice a day at $\$ 35.06(\$ 15.13-\$ 53.91)$.

\section{Likely treatment adherence}

The first stage of the adherence-rating model showed that patients were more likely to indicate that medication attributes influenced the likelihood that they would miss or skip doses if they were married, were employed, had been diagnosed with T2DM less than 2 years ago, had a college education, or had a high current-dosing burden. In contrast, older patients and patients who considered their current glucose control to be excellent were less likely to indicate that medication attributes influenced the likelihood of missing or skipping doses.

Adherence weights and the 95\% CIs from the secondstage model are presented in Figure 3. These weights show the impact of cost and dosing burden on patients' likely adherence to a T2DM treatment. Higher adherence weights indicate higher likelihood that patients would be adherent to a treatment. The results show that patients who reported having a lower current-dosing burden (noted as "light users" in Figure 3) and patients who reported having a higher currentdosing burden (noted as "heavy users" in Figure 3) placed different weights on the effect of dosing schedule on likely adherence. The impact on likely adherence of changing from three pills twice a day to two pills in the evening and one pill in the morning was comparable between the two groups. However, the impact of the remaining potential changes in daily dosing on likely adherence was greater for light users than for heavy users. In addition, while one pill twice a day was preferred to two pills once a day by both light users and heavy users, two pills once a day was rated as more likely to result in medication adherence than one pill once a day for both categories of patients.

\section{Discussion}

Antihyperglycemic therapies, such as fixed-dose combination therapies, have been developed to treat T2DM and to reduce dosing burden..$^{5-7}$ Fixed-dose combination therapies provide greater convenience for patients with T2DM taking dual therapy and potentially improve medication adherence..$^{8-11}$ Using a DCE, we estimated preference weights for seven treatment attributes (including treatment efficacy, treatmentrelated side effects, daily dosing, and cost) to quantify the WTP and relative importance of reducing dosing burden, and to estimate the potential effect of more convenient dosing on adherence.

In general, patients were willing to accept tradeoffs among treatment efficacy, treatment-related side effects, dosing, and treatment cost. As expected, on average reducing dosing burden was valued by patients; however, it was valued more by patients who were currently taking fewer daily medications than by patients who were taking more daily medications. In addition, less convenient dosing was rated by patients as

Table 3 Willingness to pay for improvements in daily dosing schedule (US\$/month)

\begin{tabular}{|c|c|c|c|}
\hline \multicolumn{2}{|l|}{ Improvements in daily dosing schedule } & \multicolumn{2}{|l|}{ WTP (95\% CI) } \\
\hline From & To & Light users & Heavy users \\
\hline Two pills in the evening & One pill in the morning, one in the evening & $\$ 35.06(\$ 15.13, \$ 53.91)$ & $\$ 1.50(\$ 0.11, \$ 8.44)$ \\
\hline Two pills in the morning, one in the evening & One pill in the morning, one in the evening & $\$ 42.82(\$ 23.70, \$ 61.01)$ & $\$ 14.9 \mid(\$ 8.05, \$ 25.72)$ \\
\hline Three pills in the morning, three in the evening & One pill in the morning, one in the evening & $\$ 66.59(\$ 45.45, \$ 87.09)$ & $\$ 28.99(\$ 19.38, \$ 38.51)$ \\
\hline Two pills in the morning, one in the evening & Two pills in the evening & $\$ 8.97(\$ 0.44, \$ 30.58)$ & $\$ 13.40(\$ 6.87, \$ 24.12)$ \\
\hline Three pills in the morning, three in the evening & Two pills in the evening & $\$ 34.89(\$ 12.74, \$ 56.16)$ & $\$ 27.69(\$ 18.46, \$ 37.18)$ \\
\hline Three pills in the morning, three in the evening & Two pills in the morning, one in the evening & $\$ 27.12(\$ 4.98, \$ 49.42)$ & $\$ 14.70(\$ 7.31, \$ 25.96)$ \\
\hline
\end{tabular}

Abbreviations: $\mathrm{Cl}$, confidence interval; WTP, willingness to pay. 


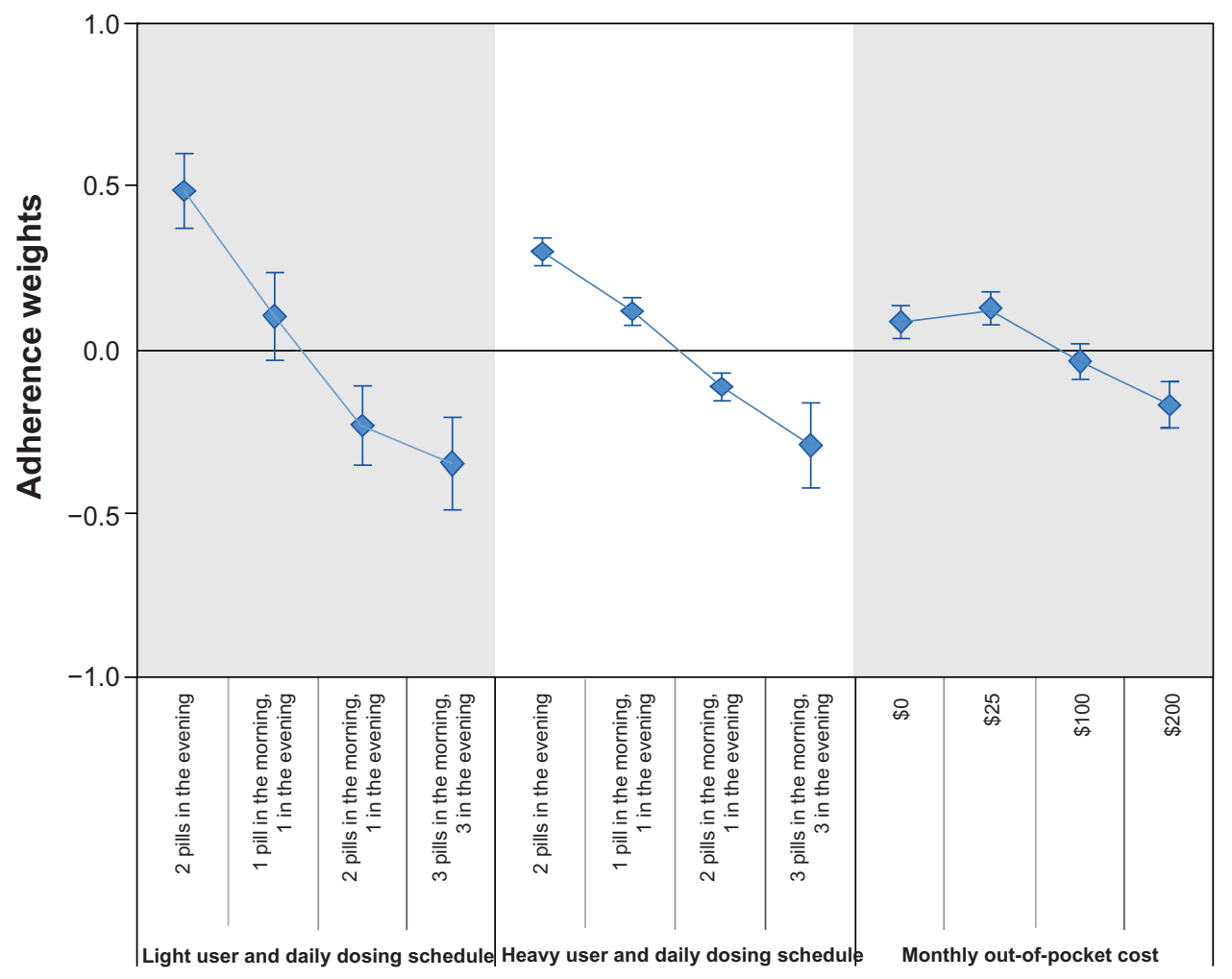

Figure 3 Adherence weights $(n=524)$. ${ }^{\text {a }}$

Note: ${ }^{\mathrm{a}}$ The vertical bars denote the $95 \%$ confidence interval around the point estimate.

more likely to result in non-adherence than more convenient dosing. Again, this effect was greater among patients with lower current pill burden or lower frequency of dosing than patients with higher current dosing burden.

A few recently published studies examined patients' preferences for attributes of oral antihyperglycemic agents ${ }^{21,32,33}$ using DCEs; however, we are aware of only one study that examined both patient preferences and the impact of treatment attributes on likely adherence. ${ }^{21}$ Similarly to this study, Hauber et $\mathrm{al}^{21}$ employed a DCE comprising attributes related to glucose control, side effects, and treatment-related risks and used a similar follow-up question to elicit patients' ratings of the impact of treatment attributes on likely adherence. Unlike the current study, the previous study by Hauber et $\mathrm{al}^{21}$ did not include dosing or cost. This previous study found that weight gain and risk of myocardial infarction influenced patients' likely adherence. In contrast, the current study found no such relationship between clinical outcomes and adherence, finding instead that only dosing schedule and out-of-pocket cost influenced patients' ratings of likely adherence. While these differences in results are interesting, it is impossible to compare the previous study by Hauber et $\mathrm{a}^{21}$ directly with this study because of differences in the attributes included in the medication profiles and differences in the study sample.
There are a number of limitations of this study that should be considered when interpreting the results. In DCEs, patients evaluate hypothetical treatments. The tradeoffs among attributes and levels in this study were intended to simulate possible clinical decisions, but they may not carry the same consequences as actual decisions. Thus, differences may arise between stated and actual choices. We tried to minimize such potential differences by offering treatment alternatives that mimic real-world tradeoffs as closely as possible. A second limitation of DCE studies concerns the ranges of attribute levels in the study. The preference weights are valid and should be interpreted only over the specific ranges of attribute levels presented in the survey. The ranges of levels for the clinical attributes included in this study were designed to encompass the ranges of outcomes seen in clinical trials of oral antihyperglycemic therapies; however, the range of cost levels included in this study was chosen to encompass the range over which patients were willing to accept tradeoffs between cost and different levels of the clinical attributes. Therefore, it is not appropriate to compare directly the relative overall importance of cost to the relative overall importance of the clinical and dosing attributes in this study.

The definition of heavy users and light users employed in this study was chosen because it identified the two subgroups 
with the greatest differences in the relative importance of dosing. These subgroups do not reflect any common clinical stratification of patients based on pill burden. Sampling was not stratified to ensure an equal number of patients in each of these subgroups. The number of light users in our sample $(n=90)$ was much smaller than the number of heavy users $(n=1,024)$. The statistical precision of the preference weights and adherence weights for light users is, therefore, lower than that for heavy users, ie, the CIs surrounding the preference weights and adherence weights for light users are larger than those for heavy users. Likewise, the CIs surrounding the WTP estimates for light users are larger than those for heavy users.

While the results of this study indicate that patients believe more convenient dosing options are likely to result in lower non-adherence to oral antihyperglycemic therapies, they do not prove that providing more convenient dosing will result in greater adherence. Firstly, the patients' ratings of the impact of medication attributes on likely non-adherence reflect patients' evaluations of what might happen rather than a measure of patients' actual changes in medication-taking behavior associated with a change in dosing. Secondly, we do not know exactly why these patients believe that more convenient dosing might lead to lower non-adherence. It could be that these patients believed that more convenient dosing would result in lower unintentional non-adherence (eg, forgetting to take medicine), or it could be that patients believed that more convenient dosing would somehow result in lower intentional non-adherence (eg, choosing not to take medications at certain times as prescribed because medication taking would interfere with some other activity). Qualitative observations from the pretest interviews indicate that more convenient dosing might improve adherence by reducing the number of opportunities for unintentional non-adherence. This is further confirmed by our finding that a change in dosing from one pill twice a day to two pills once a day was rated as decreasing the likelihood of non-adherence. In addition, patients who indicated that they never missed or skipped doses were not asked the adherence rating questions. By doing so, we assume explicitly that medication attributes do not affect the likely adherence behavior of these respondents. Whether or not this assumption reflects real-world behavior is unknown and probably unknowable.

Although recruited through a panel that is representative of US households, the respondents in this study may not be representative of US households or of people with T2DM in the US. Compared with recent data describing the characteristics of the population of people with diabetes in the
$\mathrm{US},{ }^{34}$ the respondents in our sample appear to be more highly educated than the diabetes population in the US. Minority populations appear to be underrepresented in this sample. In addition, there were some statistically significant differences in the demographic characteristics of those who responded to the survey and those who did not. On average, respondents were older, more likely to be white, more likely to be female, and less likely to be currently employed. Therefore, it appears that there was self-selection in the sample. The results of this study are likely applicable to only a subset of patients with T2DM in the US, and are likely not generalizable to a broader diabetes population.

Finally, the results of this study may not be generalizable to the total US population with T2DM for three other reasons. Firstly, the sample excluded patients currently taking injectable T2DM treatments (eg, insulin and glucagonlike-1 receptor agonist). Secondly, the fact that the sample in this survey appears to have low minority representation and is more highly educated than the overall US population is despite the fact that respondents were recruited through an internet panel whose membership is representative of all US households. Lastly, patients who completed this survey provided a self-report of a physician diagnosis of T2DM and the authors had no way of confirming this diagnosis.

\section{Conclusion}

Patients with T2DM were willing to accept tradeoffs among treatment efficacy, treatment-related side effects, daily dosing, and treatment cost. Among those with lower dosing burden, daily-dosing schedule was relatively more important than the chance of mild-to-moderate stomach problems, weight change within the first 6 months of starting treatment, and the an incremental increase in the risk of CHF, but daily-dosing schedule was relatively less important than hypoglycemia. Among those with a higher dosing burden, daily-dosing schedule was important (most differences in preference weights for different dosing schedules are statistically significant), but less important than any other attribute included in the study. All of the attributes tested, including reduction in treatment-dosing burden, are meaningful and valued by patients with T2DM. This value is higher for patients with lower dosing burden than for patients with higher dosing burden. In addition, changes in dosing schedule had a greater impact on likely adherence for patients with lower dosing burden than for patients with higher dosing burden. Understanding the extent to which patients with T2DM value reduced dosing burden and how that affects treatment adherence may provide insight into how to improve the treatment of patients with T2DM. 


\section{Acknowledgments}

This study was funded by Merck Sharp and Dohme Corp, NJ, USA. The authors express their thanks to Vikram Kilambi for his assistance with the analysis. A Brett Hauber takes responsibility for the integrity of the work as a whole, from inception to finished article.

\section{Disclosure}

Steven Han, Ira Gantz, Kaan Tunceli, Kimberly Brodovicz, Charles M Alexander, Michael Davies, Kristy Iglay, Qiaoyi Zhang, and Larry Radican were employees of Merck Sharp and Dohme Corp at the time this study was conducted. The other authors report no conflicts of interest in this work.

\section{References}

1. Centers for Disease Control and Prevention [website on the Internet] National diabetes fact sheet: national estimates and general information on diabetes and prediabetes in the United States, 2011. Atlanta: US Department of Health and Human Services, Centers for Disease Control and Prevention; 2011. Available from: http://www.cdc.gov/ diabetes/pubs/pdf/ndfs_2011.pdf. Accessed July 27, 2012.

2. Garber AJ, Abrahamson MJ, Barzilay JI, et al. AACE comprehensive diabetes management algorithm 2013. Endocr Pract. 2013;19(2): 327-336.

3. Garber AJ, Donovan DS, Dandona P, Bruce S, Park JS. Efficacy of glyburide/metformin tablets compared with initial monotherapy in type 2 diabetes. J Clin Endocrinol Metab. 2003;88(8):3598-3604.

4. Perez A, Zhao Z, Jacks R, Spanheimer R. Efficacy and safety of pioglitazone/metformin fixed-dose combination therapy compared with pioglitazone and metformin monotherapy in treating patients with T2DM. Curr Med Res Opin. 2009;25(12):2915-2923.

5. Charbonnel B, Schernthaner G, Brunetti P, et al. Long-term efficacy and tolerability of add-on pioglitazone therapy to failing monotherapy compared with addition of gliclazide or metformin in patients with type 2 diabetes. Diabetologia. 2005;48(6):1093-1104.

6. Charbonnel BH, Matthews DR, Schernthaner G, Hanefeld M, Brunetti P; QUARTET Study Group. A long-term comparison of pioglitazone and gliclazide in patients with type 2 diabetes mellitus: a randomized, double-blind, parallel-group comparison trial. Diabet Med. 2005;22(4):399-405.

7. Nauck MA, Meininger G, Sheng D, Terranella L, Stein PP; Sitagliptin Study 024 Group. Efficacy and safety of the dipeptidyl peptidase-4 inhibitor, sitagliptin, compared with the sulfonylurea, glipizide, in patients with type 2 diabetes inadequately controlled on metformin alone: a randomized, double-blind, non-inferiority trial. Diabetes Obes Metab. 2007;9(2):194-205.

8. Bae JP, Dobesh PP, Klepser DG, et al. Adherence and dosing frequency of common medications for cardiovascular patients. Am J Manag Care. 2012;18(3):139-146.

9. Claxton AJ, Cramer J, Pierce C. A systematic review of the associations between dose regimens and medication compliance. Clin Ther. 2001;23(8):1296-1310.

10. Richter A, Anton SE, Koch P, Dennett SL. The impact of reducing dose frequency on health outcomes. Clin Ther. 2003;25(8):2307-2335.

11. Saini SD, Schoenfeld P, Kaulback K, Dubinsky MC. Effect of medication dosing frequency on adherence in chronic diseases. Am J Manag Care. 2009;15(6):e22-e33.

12. Bridges JFP, Kinter ET, Kidane L, Heinzen RR, McCormick C. Things are looking up since we started listening to patients: trends in the application of conjoint analysis in health 1982-2007. Patient. 2008;1(4): 273-282.
13. Marshall D, Bridges JFP, Hauber AB, et al. Conjoint analysis applications in health - how are studies being designed and reported? An update on current practice in the published literature between 2005 and 2008. Patient. 2010;3(4):249-256.

14. de Bekker-Grob EW, Ryan M, Gerard K. Discrete choice experiments in health economics: a review of the literature. Health Econ. 2012;21(2): $145-172$.

15. Hensher DA, Rose JM, Greene WH. Applied Choice Analysis. Cambridge (UK): Cambridge University Press; 2005.

16. Hauber AB, Gonzalez JM, Schenkel B, Lofland J, Martin S. The value to patients of reducing lesion severity in plaque psoriasis. J Dermatolog Treat. 2011;22(5):266-275.

17. Johnson FR, Mohamed AF, Ozdemir S, Marshall DA, Phillips KA. How does cost matter in health-care discrete-choice experiments? Health Econ. 2011;20(3):323-330.

18. Johnson FR, Banzhaf MR, Desvousges WH. Willingness to pay for improved respiratory and cardiovascular health: a multiple-format stated-preference approach. Health Econ. 2000;9(4):295-317.

19. Hauber AB, González JM, Coombs J, Sirulnik A, Palacios D, Scherzer N. Patient preferences for reducing toxicities of treatments for gastrointestinal stromal tumor (GIST). Patient Prefer Adherence. 2011;5:307-314

20. Hauber AB, Mohamed AF, Beam C, Medjedovic J, Mauskopf J. Patient preferences and assessment of likely adherence for hepatitis $\mathrm{C}$ virus treatments. J Viral Hepat. 2011;18(9):619-627.

21. Hauber AB, Mohamed AF, Johnson FR, Falvey H. Treatment preferences and medication adherence of people with type 2 diabetes using oral glucose-lowering agents. Diabet Med. 2009;26(4):416-424.

22. Johnson FR, Ozdemir S, Manjunath R, Hauber AB, Burch SP, Thompson TR. Factors that affect adherence to bipolar disorder treatments: a stated-preference approach. Med Care. 2007;45(6):545-552.

23. Dey A. Orthogonal Fractional Factorial Designs. New York: Halstead Press; 1985.

24. Huber J, Zwerina K. The importance of utility balance in efficient choice designs. J Marketing Res. 1996;33:307-317.

25. Kanninen BJ. Optimal design for multinomial choice experiments. $J$ Market Res. 2002;39(2):214-227.

26. Kuhfeld W. Marketing Research Methods in SAS: Experimental Design, Choice, Conjoint, and Graphical Techniques. Cary (NC): SAS Institute Inc; 2010

27. Kuhfeld W, Tobias F, Garratt M. Efficient experimental design with marketing research applications. J Mark Res. 1994;31(4):545-557.

28. Zwerina K, Huber J, Kuhfeld W. A General Method for Constructing Efficient Choice Designs. Durham (NC): Fuqua School of Business, Duke University; 1996.

29. Greene WH. Econometric Analysis. 5th ed. Upper Saddle River (NJ): Prentice Hall; 2003.

30. Heckman J. The common structure of statistical models of truncation, sample selection, and limited dependent variables and a simple estimator for such models. Ann Econ Soc Meas. 1976;5(4):475-492.

31. Heckman J. Sample selection bias as a specification error. Econometrica. 1979;47(1):153-161.

32. Jendle J, Torffvit O, Ridderstråle M, Ericsson Å, Nilsen B, Bøgelund M. Willingness to pay for diabetes drug therapy in type 2 diabetes patients: based on LEAD clinical programme results. $J \mathrm{Med}$ Econ. 2012;15 Suppl 2:1-5.

33. Porzsolt F, Clouth J, Deutschmann M, Hippler HJ. Preferences of diabetes patients and physicians: a feasibility study to identify the key indicators for appraisal of health care values. Health Qual Life Outcomes. 2010;8:125.

34. Zhang X, Bullard KM, Gregg EW, et al. Access to health care and control of ABCs of diabetes. Diabetes Care. 2012;35(7):1566-1571. 


\section{Supplementary table}

Table SI Literature reviewed in determining attributes and levels

\begin{tabular}{|c|c|}
\hline Attribute & Publication reviewed \\
\hline \multirow[t]{21}{*}{ Blood sugar control } & Bruce S, Park JS, Fiedorek FT, Howlett HC. Beta-cell response to metformin-glibenclamide combination tablets \\
\hline & (Glucovance) in patients with type 2 diabetes. Int J Clin Pract. 2006;60(7):783-790. \\
\hline & Charbonnel B, Schernthaner G, Brunetti P, et al. Long-term efficacy and tolerability of add-on pioglitazone therapy to \\
\hline & failing monotherapy compared with addition of gliclazide or metformin in patients with type 2 diabetes. Diabetologia. \\
\hline & 2005;48(6): 1093-II04. \\
\hline & Fujioka K, Pans M, Joyal S. Glycemic control in patients with type 2 diabetes mellitus switched from twice-daily \\
\hline & immediate release metformin to a once-daily extended-release formulation. Clin Ther. 2003;25:5I5-529. \\
\hline & Garber AJ, Donovan DS Jr, Dandona P, Bruce S, Park JS. Efficacy of glyburide/metformin tablets compared with initial \\
\hline & monotherapy in type 2 diabetes. J Clin Endocrinol Metab. 2003;88(8):3598-3604. \\
\hline & Goldstein BJ, Feinglos MN, Lunceford JK, Johnson J, Williams-Herman DE; Sitagliptin 036 Study Group. Effect of initial \\
\hline & combination therapy with sitagliptin, a dipeptidyl peptidase- 4 inhibitor, and metformin on glycemic control in patients \\
\hline & with type 2 diabetes. Diabetes Care. 2007;30(8): I979-1987. \\
\hline & Marre M, Howlett H, Lehert P, Allavoine T. Improved glycaemic control with metformin-glibenclamide combined tablet \\
\hline & therapy (Glucovance ${ }^{\circledR}$ ) in Type 2 diabetic patients inadequately controlled on metformin. Diabet Med. 2002;19(8):673-680. \\
\hline & Nauck MA, Meininger G, Sheng D, Terranella L, Stein PP; Sitagliptin Study 024 Group. Efficacy and safety of the dipeptidyl \\
\hline & peptidase-4 inhibitor, sitagliptin, compared with the sulphonylurea, glipizide, in patients with type 2 diabetes inadequately \\
\hline & controlled on metformin alone: a randomized, doubleblind, non-inferiority trial. Diabetes Obes Metab. 2007;9(2): 194-205. \\
\hline & Perez A, Zhao Z, Jacks R, Spanheimer R. Efficacy and safety of pioglitazone/metformin fixed-dose combination \\
\hline & therapy compared with pioglitazone and metformin monotherapy in treating patients with T2DM. Curr Med Res Opin. \\
\hline & 2009;25(I2):2915-2923. \\
\hline & Rodríguez Á, Ciprés L, Tofé S, Polavieja P, Reviriego J. Clinical evaluation of combined therapy for type 2 diabetes. Curr \\
\hline
\end{tabular}

Rodríguez Á, Ciprés L, Tofé S, Polavieja P, Reviriego J. Clinical evaluation of combined therapy for type 2 diabetes. Curr Med Res Opin. 2010;26(5): I I7I-II83.

Umpierrez G, Issa M, Vlajnic A. Glimepiride versus pioglitazone combination therapy in subjects with type 2 diabetes inadequately controlled on metformin monotherapy: results of a randomized clinical trial. Curr Med Res Opin. 2006;22(4):75I-759.

Stomach problems $\quad$ Blonde L, Dailey GE, Jabbour SA, Reasner CA, Mills DJ. Gastrointestinal tolerability of extended-release metformin tablets compared to immediate-release metformin tablets: results of a retrospective cohort study. Curr Med Res Opin. 2004;20(4):565-572.

Feher MD, Al-Mrayat M, Brake J, Leong KS. Tolerability of prolonged-release metformin (Glucophage SR) in individuals intolerant to standard metformin-results from four UK centres. Br J Diabetes Vasc Dis. 2007;7:225-228. Fujioka K, Pans M, Joyal S. Glycemic control in patients with type 2 diabetes mellitus switched from twice-daily immediate release metformin to a once-daily extended-release formulation. Clin Ther. 2003;25(2):5I5-529. Gao Y, Li G, Li Y, et al. Postprandial blood glucose response to a standard test meal in insulin-requiring patients with diabetes treated with insulin lispro mix 50 or human insulin mix 50. Int J Clin Practice. 2008;62(9): I344-I35।. Garber AJ, Duncan TG, Goodman AM, Mills DJ, Rohlf JL. Efficacy of metformin in type II diabetes: results of a doubleblind placebo-controlled dose response trial. Am J Med. 1997; 103(6):49I-497.

Garber AJ, Larsen J, Schneider SH, Piper BA, Henry D; Glyburide/Metformin Initial Therapy Study Group. Simultaneous glyburide/metformin therapy is superior to component monotherapy as an initial pharmacological treatment for type 2 diabetes. Diabetes Obes Metab. 2002;4(4):286.

Goldstein BJ, Feinglos MN, Lunceford JK, Johnson J, Williams-Herman DE; Sitagliptin 036 Study Group. Effect of initial combination therapy with sitagliptin, a dipeptidyl peptidase-4 inhibitor, and metformin on glycemic control in patients with type 2 diabetes. Diabetes Care. 2007;30(8):1979-1987.

Levy J, Cobas RA, Gomes MB. Assessment of efficacy and tolerability of once-daily extended release metformin in patients with type 2 diabetes mellitus. Diabetol Metab Syndr. 2010;2: 16.

Schwartz S, Fonseca V, Berner B, Cramer M, Chiang YK, Lewin A. Efficacy, tolerability, and safety of a novel once-daily extended-release metformin in patients with type 2 diabetes. Diabetes Care. 2006;29(4):759-764.

Hypoglycemia Dibonaventura MD, Wagner JS, Girman CJ, et al. Multinational Internet-based survey of patient preference for newer oral or injectable type 2 diabetes medication. Patient Prefer Adherence. 2010;4:397-406.

Feher MD, Al-Mrayat M, Brake J, Leong KS. Tolerability of prolonged-release metformin (Glucophage SR) in individuals intolerant to standard metformin-results from four UK centres. Br J Diabetes Vasc Dis. 2007;7:225-228. 
Table SI (Continued)

\begin{tabular}{ll}
\hline Attribute & Publication reviewed \\
\hline Weight change & Dibonaventura MD, Wagner JS, Girman CJ, et al. Multinational Internet-based survey of patient preference for newer \\
& oral or injectable type 2 diabetes medication. Patient Prefer Adherence. 20I0;4:397-406. \\
& Feher MD, Al-Mrayat M, Brake J, Leong KS. Tolerability of prolonged-release metformin (Glucophage SR) \\
& in individuals intolerant to standard metformin-results from four UK centres. Br J Diabetes Vasc Dis. 2007;7:225-228. \\
& Home PD, Pocock SJ, Beck-Nielsen H, et al; RECORD Study Team. Rosiglitazone evaluated for cardiovascular outcomes \\
Congestive heart & in oral agent combination therapy for type 2 diabetes (RECORD): a multicentre, randomised, open-label trial. Lancet. \\
failure & $2009 ; 373(968 I): 2$ I 25-2I35.
\end{tabular}

\section{Publish your work in this journal}

Patient Preference and Adherence is an international, peer-reviewed, open access journal focusing on the growing importance of patient preference and adherence throughout the therapeutic continuum. Patient satisfaction, acceptability, quality of life, compliance, persistence and their role in developing new therapeutic modalities and compounds to
Dovepress

optimize clinical outcomes for existing disease states are major areas of interest. This journal has been accepted for indexing on PubMed Central. The manuscript management system is completely online and includes a very quick and fair peer-review system. Visit http://www.dovepress.com/ testimonials.php to read real quotes from published authors.

\footnotetext{
Submit your manuscript here: http://www.dovepress.com/patient-preference-and-adherence-journal
} 